\title{
RECOMMENDATIONS FOR THE DESIGN AND PERFORMANCE OF ELECTROENCEPHALOGRAPHIC APPARATUS
}

BY

\author{
G. D. DAWSON * \\ (The Neurological Research Unit, National Hospital, Queen Square) \\ AND \\ W. GREY WALTER \\ (The Burden Neurological Institute) \\ (RECEIVED 24TH NOVEMBER, 1945)
}

WITH the return of peaceful conditions the number of centres wishing to install electroencephalographic apparatus is likely to increase and the question of the supply of such apparatus to become acute.

Already in the United States the difficulty of obtaining adequate apparatus has been pointed out (Gibbs and Lennox, 1944) and apprehension has been aroused by the poor performance of badly designed apparatus at present on the market in that country (Max, Wiesner, and Bullowa, 1943). There is no doubt that bad performance of apparatus leads to inferior results and may lead to the growth of dangerous fallacies. The development of apparatus for the purpose of electroencephalography is not difficult, but the aim must be a very high standard of performance. In the near future English equipment will probably be available and in order to provide both users and manufacturers with a clear idea of the level below which it is considered performance should not fall, a list of recommendations has been prepared at the request of the EEG Society. These recommendations have been accepted by the Ministry of Health as a basis for the development of equipment to be used in hospitals and clinics. It must be strongly emphasized that this performance is not an unattained ideal, but is that of existing apparatus, both of amateur and commercial make. The rather rigorous specification of certain controls may seem dogmatic but such standardization is desirable if the records made at various centres are to be comparable.

It is hoped that a thoroughly critical approach to the subject on the part of intending users of such apparatus will discourage the manufacture and sale of inferior and untrustworthy instruments. The recommendations referred to above are as follows.

\section{General Considerations}

Amplifiers intended only to drive direct recording oscillographs for EEG purposes need not respond to such a wide band of frequencies as those to be

* Work undertaken while working on behalf of the Medical Research Council. used for electromyography or for the recording of nerve action potentials. These recommendations are primarily concerned with amplifiers and recorders for EEG work; but an amplifier for general physiological work, which will be referred to as a " universal " amplifier, has little more cost or complexity than an amplifier made solely for the more limited application. Therefore it is usually economical to make the voltage amplifying section of any recording equipment universal and to make provision for connecting to the output a recording instrument of general utility as well as the power amplifier for driving the direct recording oscillograph for EEGs. The details of the recommendations below refer to the combination of an EEG amplifier and direct recording oscillograph except where stated.

\section{General Characteristics}

\section{(a) For each Amplifying Channel}

\section{Linearity of Response}

The deflection given by the recording instrument on the record should be directly proportional to the voltage applied to the input of the apparatus to within 10 per cent. over a range of 90 per cent. of the maximum recordable amplitude.

\section{Amplification}

(i) At the maximum setting this should be such that an input voltage change of 5 microvolts $(\mu \mathrm{V})$ will give a deflection not less than 20 per cent. of the maximum recordable deflection.

(ii) The ratio between the maximum deflection proportional to the input voltage, and the minimum visible deflection, should be not less than 40 to 1 .

(iii) The control of amplification should be by two controls, the first continuously variable from maximum to less than 1 per cent. of this; the second variable in nine steps, each providing an attenuation by a half, or $6 \mathrm{db}$. Two other steps, one giving zero attenuation and one giving infinite attenuation, should be provided. 


\section{Frequency Response}

(i) Between the limits specified below the response of the apparatus to any two frequencies should not vary by more than 15 per cent.; i.e. the frequency response curve of the apparatus" should be flat to within plus or minus $7 \frac{1}{2}$ per cent. over that range. Fig. 1 shows the response of a typical instrument to an input voltage of constant size and steadily decreasing frequency from $150 \mathrm{c} . / \mathrm{s}$. to $1.5 \mathrm{c} . / \mathrm{s}$. Fig. 2 shows a response curve of peak to peak amplitude of deflection plotted against frequency from $1 \mathrm{c} . / \mathrm{s}$. to $100 \mathrm{c} . / \mathrm{s}$., derived from a similar record made at a faster paper rate to resolve the individual waves at the higher frequencies. It shows that the response between $1 \mathrm{c} . / \mathrm{s}$. and $85 \mathrm{c} . / \mathrm{s}$. is within plus or minus 6 per cent. of that at $10 \mathrm{c} . / \mathrm{s}$.

(ii) Lower Frequencies. The overall time constant of the system should be variable in four steps with the following values: a maximum not less than $1 \mathrm{sec}$., $0.30 \mathrm{sec}$., $0.10 \mathrm{sec}$, and $0.03 \mathrm{sec}$., corresponding to not more than 10 per cent. attenuation of the response to frequencies of $0.35 \mathrm{c} . / \mathrm{s} ., 1 \cdot 2 \mathrm{c} . / \mathrm{s}$., 3.5 c./s., and 12 c./s., respectively.

(iii) Upper Frequencies.-Three settings for upper frequency response should be provided giving not more than 15 per cent. attenuation at $75 \mathrm{c} . / \mathrm{s}$., $25 \mathrm{c} . / \mathrm{s}$., and $15 \mathrm{c} . / \mathrm{s}$., and a progressive reduction in response above these frequencies not less rapid, and preferably not more rapid, than may be obtained with a single shunt capacitance filter. In addition, if the voltage amplifying section of the equipment is to be used as a universal amplifier, there should be two further settings giving not more than 15 per cent. attenuation of frequencies of $5,000 \mathrm{c} . / \mathrm{s}$. and $500 \mathrm{c} . / \mathrm{s}$.

\section{Coupling of Controls}

The operation of any one control should not alter the effective setting of any other control by more than 15 per cent. For example, a change in the amplification controls should not affect the frequency response of the apparatus by more than this amount.

\section{Basic Irregularity ("Noise Level")}

With the input short circuited and the controls set to give an equal response to all frequencies between $0.35 \mathrm{c} . / \mathrm{s}$. and $75 \mathrm{c}$. $/ \mathrm{s}$. no deflections should appear in the record greater than would be produced by an input voltage of $2 \mu \mathrm{V}$ peak to peak. This degree of irregularity is the greatest that should be allowed. It is in fact possible for these irregularities to be reduced to less than would be produced by an input of $1, \mu \mathrm{V}$ peak to peak and it is desirable that this should be done to allow a margin of safety. Examples of levels of basic irregularity are shown in Fig. 3A and B, at different recording speeds. In these records the same input, a rectangular wave of $5 \mu \mathrm{V}$, was applied to the inputs of all four channels at once. Channels 3 and 4 are considered good, the irregularity being not more than $1 \mu \mathrm{V}$ peak to peak, channel 1 is considered as just satisfactory, and channel 2 as in need of attention.

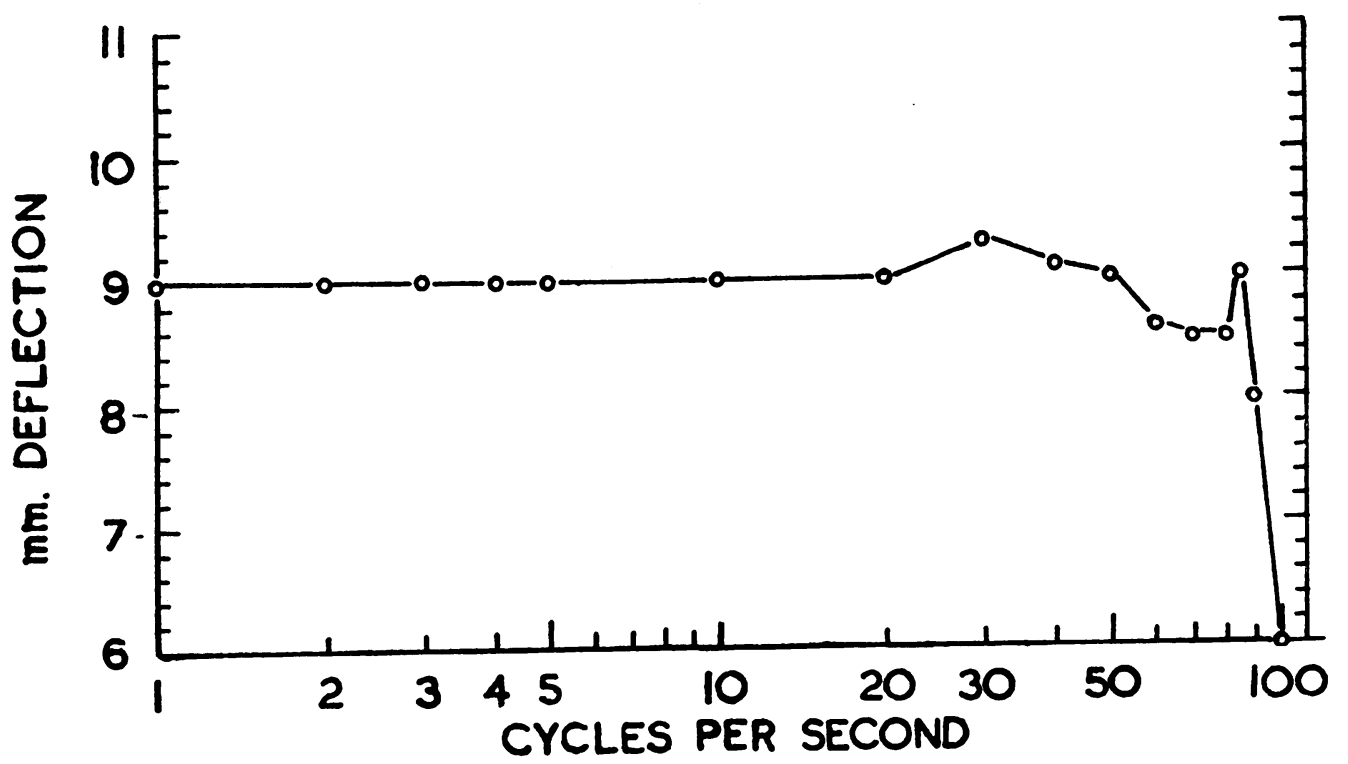

FIG. 2.-Graph of amplitude of response to inputs of frequency between $1 \mathrm{c} / \mathrm{s}$. and $100 \mathrm{c} / \mathrm{s}$. and of constant size. 

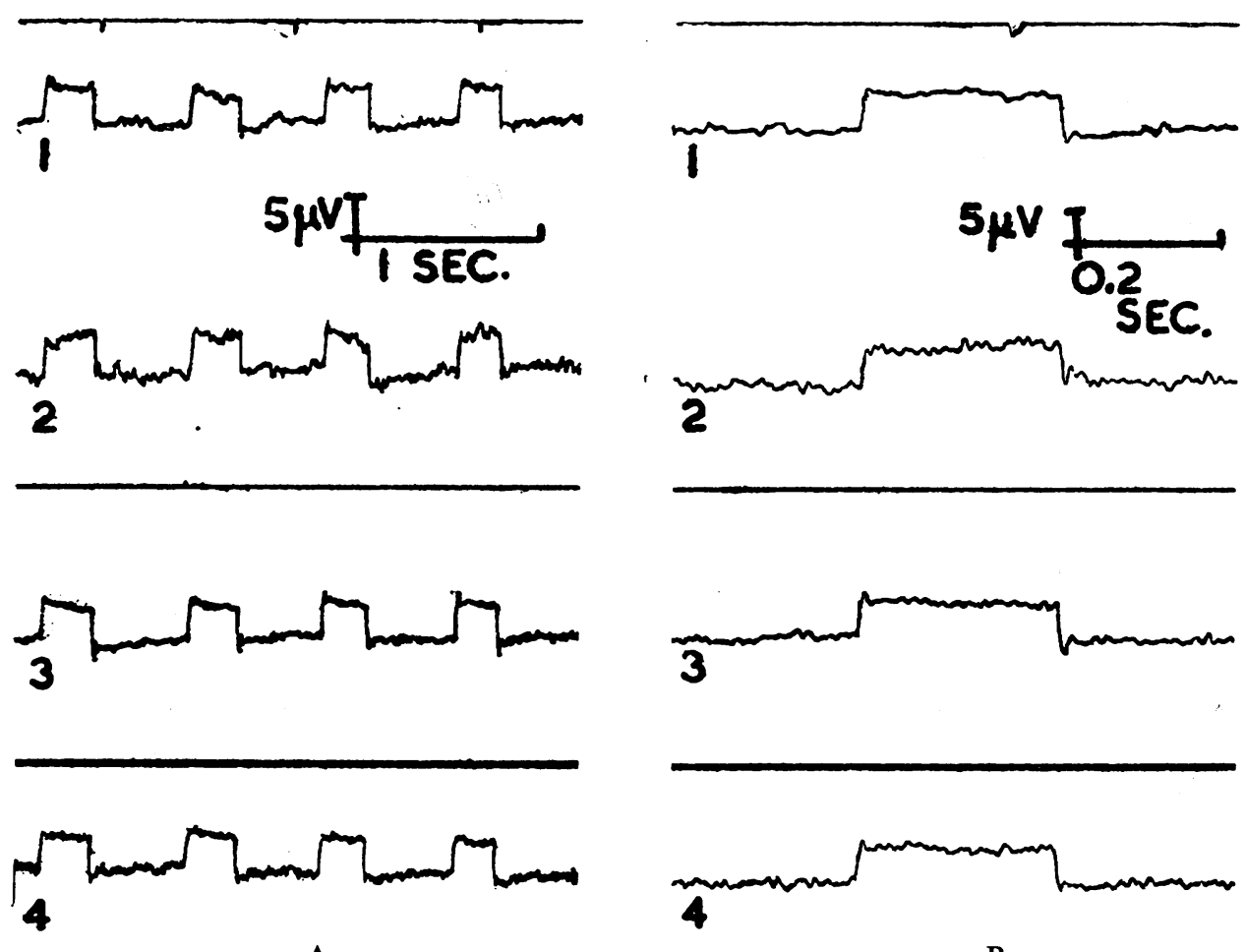

A

B

FIG. 3.-Response of four channels to an input of 5 microvolts amplitude and rectangular form at recording speeds of (A) $2 \mathrm{~cm}$. per sec. and (B) $7.5 \mathrm{~cm}$. per sec. The level of irregularity in channels 3 and 4 is good, less than $1 \mu \mathrm{V}$ peak to peak; in channel 1 it is just satisfactory and in channel 2 poor.

\section{Discrimination}

With the two input terminals connected together, a potential difference applied between them and earth should not produce a deflection more than 1 per cent. of that produced by the same potential difference applied between the two input terminals.

\section{Construction}

The construction of the apparatus should be such that no external insulation from mechanical vibration or noise is required to prevent damage or spurious deflections in the record.

\section{Constancy}

The above conditions should be attained within 15 minutes of switching on and should be maintained for a period of 24 hours of continuous running.

\section{Life}

The above conditions should be maintained for a period of 1,000 hours use or 2 years from the date of installation, whichever is the less, exclusive of battery replacements.

\section{Safety}

The apparatus should in all respects conform to the recommendations of the I.E.E. regarding the safety of the patient and operator.

\section{(b) In Addition for Multi-channel Equipments}

\section{Inter-channel Coupling}

A potential difference applied to the input of one channel only should not produce a deflection in any other channel greater than 1 per cent. of that in the channel to which the potential difference is applied.

\section{Limitation of Arc Distortion}

Maximum deflection of one recorder should not produce a loss of registration with any other recorder, at any deflection, greater than 10 per cent. of the maximum peak to peak deflection of the recorder. At zero deflection all the recorder writing points should lie on a line perpendicular to the time axis of the record, in the plane of the record.

\section{Similarity of Channels}

In a multi-channel instrument the several channels should be as nearly identical as possible. In practice with all step controls, that is to say the step attenuator, time constant, and filter controls, set to the same positions and the continuously variable attenuator suitably adjusted, an identical input signal applied simultaneously to the inputs of all channels should give records from them all that are superimposable to within 5 or 10 per cent.

14. Circuit

\section{Detailed Characteristics}

The circuit arrangement should be such as to conform with the general specification and should fulfil the following additional requirements:-

(a) Not more than the first two stages of each channel should be battery operated and accommodation should be provided for such batteries.

(b) Provided the requirements of the general specification are fulfilled, the same batteries may be employed to provide power supplies for more than one channel. 
(c) In universal amplifiers a socket should be provided for the connection of auxiliary recording devices to the last voltage amplifying stage.

\section{Calibrator}

At the input of the amplifier a calibrating circuit should be provided giving an input voltage of rectangular waveform in single pulses adjustable in size from $5 \mu \mathrm{V}$ to $1 \mathrm{mV}$.

\section{Leads}

Input leads should be provided and fitted with appropriate clips and plugs to suit individual requirements. They should be screened and the screen should be securely attached to the common earth.

Mains leads should be screened and earthed as above.

\section{Recorder}

The recorder should be such as to produce an immediately visible and permanent record. The cost of the recording material should not exceed $5 /$ - (five shillings) for 1 hour's recording at the lowest speed.

In the case of multi-channel instruments the distance between the writing points of two adjacent recorders at maximum deflection in opposite phase should be not greater than 10 per cent. of the maximum peak to peak deflection of the recorders.

Six hours continuous recording should be possible without replacement of recording materials.

\section{Recording Surface Speed}

Three speeds should be provided. The lowest of these speeds should be such that the distance travelled by the recording surface in $1 \mathrm{sec}$. should be approximately equal to the maximum peak to peak deflection of a single recorder. The higher speeds should be twice and four times this rate, these speeds to be selectable while running.

\section{Recording Surface Travel}

The recording surface should travel from the operator's right to left and should be visible for a space of not less than $15 \mathrm{~cm}$. to the left of the recording line.

\section{Adjustment of Recorders}

The position of each recorder should be adjustable for:- (a) Pressure on the recording surface.

(b) Registration in line with the other recorders, at right angles with the direction of travel of the recording surface.

\section{Time Marker}

A time marker, registered with the recorders, should be provided to mark on the recording surface. This time marker should provide marks at 1-sec. intervals and the accuracy of these marks should be not less than that of a synchronous motor run on the mains supply available.

\section{Signal Marker}

A signal marker, registered with the recorders, should be provided to mark on the recording surface. This should be connected internally with a low voltage supply and should have a socket for external keying as well as a built-in operating key.

\section{Pilot Light}

A pilot light should be provided to indicate when any power supply is switched on.

\section{Meter}

A meter should be provided connectable to each battery power supply to indicate when such batteries need recharging or replacing.

\section{Height}

In a static equipment the height of the recording surface should be not less than $30 \mathrm{in}$. and not more than 45 in.

\section{Portable Apparatus}

In the case of portable apparatus the whole equipment should be contained in not more than two units, neither of which should weigh more than $50 \mathrm{lb}$. (fifty pounds) inclusive of all power supplies and accessories. A carrying handle should be provided such that each unit can be carried in one hand.

\section{Finish}

All exposed surfaces should be resistant to the action of saline solution and any recording fluids that may be used.

\section{REFERENCES}

Gibbs, F. A., and Lennox, W. G. (1944). Amer. J. Psychiat, 100, 544.

Max, W., Wiesner, L., and Bullowa, J. G. M. (1943). J. Lab. Alin. Med., 28, 1868. 